\title{
Cultura de segurança do paciente entre profissionais de enfermagem no ambiente da terapia intensiva*
}

\section{Patient safety culture among nursing professionals in the intensive care environment Cultura de seguridad del paciente entre profesionales de enfermería en el ámbito de los cuidados intensivos}

Como citar este artigo:

Campelo CL, Nunes FDO, Silva LDC, Guimarães LF, Sousa SMA, Paiva SS. Patient safety culture among nursing professionals in the intensive care environment. Rev Esc Enferm USP. 2021;55:e03754. https://doi.org/10.1590/S1980-220X2020016403754

\section{Cleber Lopes Campelo ${ }^{1}$}

Flávia Danyelle Oliveira Nunes ${ }^{2}$

Líscia Divana Carvalho Silva²

Laryssa Ferreira Guimarães ${ }^{3}$

Santana de Maria Alves de Sousa ${ }^{4}$

Sirliane de Souza Paiva ${ }^{2}$

* Extraído da dissertação: "Cultura de segurança do paciente em terapia intensiva na perspectiva de profissionais de Enfermagem”,

Programa de Pós-Graduação em Enfermagem, Universidade Federal do Maranhão, 2018.

${ }^{1}$ Universidade Federal do Maranhão, Programa de Pós-Graduação em Saúde Coletiva, São Luís, MA, Brasil.

${ }^{2}$ Universidade Federal do Maranhão, Departamento de Enfermagem, São Luís, MA, Brasil.

${ }^{3}$ Universidade Federal do Maranhão, Grupo de Pesquisa Habilidades Psicomotoras para o Cuidado, São Luís, MA, Brasil.

${ }^{4}$ Universidade Federal do Maranhão,

Programa de Pós-Graduação em

Enfermagem, São Luís, MA, Brasil.

\begin{abstract}
Objective: To analyze the patient safety culture among intensive care nursing professionals. Method: This is a cross-sectional study carried out in Intensive Care Units of a public hospital. Data collection was carried out from September to October 2017 with nursing professionals, using the Hospital Survey on Patient Safety Culture questionnaire. Cronbach's Alpha, Pearson's Chi-Square or Fischer's Exact tests (5\% significance level) were performed. Results: The final sample consisted of a total of 163 nursing professionals. No strong areas were observed for patient safety. The dimensions "teamwork in the unit", "expectations and actions of the supervisor/manager for the promotion of patient safety" and "organizational learning and continuous improvement" had the highest rates of positive responses, whereas the dimensions "opening for communication" and "feedback and communication about the error" had the lowest percentages. The general degree of patient safety was considered very good $72(47 \%)$ and underreporting of the events was observed, most of them were carried out by nurses. Conclusion: No dimension assessed was considered to be a strong area. However, most were shown to be potential areas for patient safety culture.
\end{abstract}

\section{DESCRIPTORS}

Patient Safety; Organizational Culture; Intensive Care Units; Nursing. 


\section{INTRODUÇÃO}

A cultura de segurança do paciente (CSP) determina o compromisso, o estilo e a competência das instituições de saúde. Seu desenvolvimento é fortemente influenciado pelo comportamento dos profissionais de saúde que, por sua vez, sofrem influência direta da gestão organizacional ${ }^{(1)}$.

O Programa Nacional de Segurança do Paciente conceitua a CSP como necessária a todos os trabalhadores, incluindo os profissionais envolvidos no cuidado e os gestores que devem priorizar a segurança acima das metas financeiras, encorajando, assim, a identificação, a notificação e a resolução dos Eventos Adversos (EA) para que, a partir dessas ocorrências, se promova o aprendizado organizacional ${ }^{(2)}$.

Instituições que criam e estabelecem uma cultura positiva obtêm melhores indicadores de saúde em consequência de ações baseadas em confiança mútua, pela percepção comum do papel da segurança do paciente na prevenção dos $\mathrm{EA}^{(3)}$. Apesar de obrigatórias desde 2014, as notificações de EA no Brasil ainda são pouco investigadas. Dados do Sistema de Notificações para a Vigilância Sanitária (Notivisa), de 2014 a 2016, apontaram a ocorrência de 63.933 eventos no Brasil, com 417 pacientes que evoluíram para óbito, a maioria $(96,6 \%)$ no ambiente hospitalar durante a prestação de cuidado ${ }^{(4)}$.

A ocorrência desses eventos reflete o distanciamento entre o cuidado real e o ideal, constituindo um dos maiores desafios para a segurança do paciente ${ }^{(5)}$. Dentre os ambientes de risco em uma unidade hospitalar, as unidades de terapia intensiva (UTI) mostram-se como um cenário potencial para a ocorrência de EA em virtude da gravidade dos pacientes, complexidade de intervenções terapêuticas e grande número de dispositivos tecnológicos ${ }^{(6)}$.

Entre os membros da equipe multiprofissional que atuam na UTI, a Enfermagem constitui a maior força de trabalho, com mais de um milhão de trabalhadores no Brasil, sendo que, dentro desse ambiente, a carga de trabalho desses profissionais se mostra diretamente associada à ocorrência de $\mathrm{EA}^{(5)}$, o que remete à necessidade de compreensão por parte desses profissionais sobre o erro na assistência à saúde e suas consequências, buscando a melhoria do cuidado e a prevenção de complicações.

Diante desse contexto, a segurança do paciente requer uma prática com o mínimo de atos inseguros, que alcance os melhores resultados para o paciente. Dessa forma, avaliar a CSP é importante para medir as condições organizacionais que levam a possíveis danos aos pacientes nos serviços de saúde ${ }^{(7)}$. Assim, o objetivo deste estudo foi analisar a CSP na perspectiva de profissionais de enfermagem no âmbito da terapia intensiva.

\section{MÉTODO}

\section{TIPO DE ESTUDO}

Trata-se de um estudo transversal e de abordagem quantitativa.

\section{CenÁrio}

O estudo foi desenvolvido em quatro UTI - uma UTI Cirúrgica, uma UTI Cardiológica e duas UTI Gerais - de um hospital público da rede estadual de saúde, localizado na cidade de São Luís, Maranhão, Brasil. Trata-se de um hospital de alta complexidade que possui cerca de 216 leitos para assistência nas especialidades médicas e cirúrgicas, sendo 47 leitos destinados à terapia intensiva.

\section{População}

A população foi composta por 200 profissionais de enfermagem, em contato direto com os pacientes ou que não estavam em contato direto, mas cujas funções afetavam o seu cuidado e que exerciam suas atividades nas quatro UTI. Foram estabelecidos como critérios de inclusão ser enfermeiro ou técnico de enfermagem, com carga horária semanal mínima de 20 horas.

Foram excluídos os participantes de licença saúde, sem vencimento ou maternidade, bem como aqueles que responderam menos de uma seção inteira do instrumento, responderam menos da metade dos itens de todo o instrumento em diferentes seções e os que apresentaram a mesma resposta em todos os itens, denotando, assim, que o participante não dispensou a atenção necessária ao preenchimento do instrumento.

A amostragem foi não probabilística, por conveniência. A amostra final foi composta por 163 profissionais de enfermagem, sendo 42 enfermeiros e 121 técnicos de enfermagem. Desse total, 11 enfermeiros e 25 técnicos de enfermagem eram lotados na UTI Cirúrgica, 9 enfermeiros e 30 técnicos de enfermagem na UTI Cardiológica, 12 enfermeiros e 32 técnicos de enfermagem na UTI Geral I, 10 enfermeiros e 34 técnicos de enfermagem na UTI Geral II.

\section{Colleta DE DAdos}

A coleta de dados aconteceu nos meses de setembro e outubro de 2017. Os participantes foram abordados individualmente durante seu turno de trabalho, quando estavam disponíveis, e foram orientados quanto aos objetivos da pesquisa e ao preenchimento do instrumento. A devolutiva deste ocorreu nessa mesma oportunidade. Com os profissionais que, por algum motivo, não apresentaram disponibilidade para responder na data da abordagem, os pesquisadores realizaram tentativas em três datas subsequentes.

O instrumento utilizado foi o questionário Hospital Survey on Patient Safety Culture (HSOPSC), criado pela Agency for Healthcare Research and Quality (AHRQ) ${ }^{(8)}$. Trata-se de um instrumento já traduzido e validado para o português do Brasil, que tem por objetivo avaliar as múltiplas dimensões da CSP.

O questionário é composto por nove seções que englobam 53 itens, dos quais 42 estão relacionados a questões específicas de CSP, distribuídas em 12 dimensões: 1. Trabalho em equipe dentro das unidades; 2 . Expectativas e ações de promoção de segurança do supervisor/chefia; 3 . Aprendizado organizacional - melhoria contínua; 4. Apoio da gestão hospitalar para segurança do paciente; 5 . Percepção geral da segurança do paciente; 6 . Retorno das informações e da comunicação sobre erros; 7. Abertura para comunicação; 8. Frequência de eventos notificados; 9. Trabalho em equipe 
entre as unidades hospitalares; 10. Adequação de profissionais; 11. Passagem de plantão/turno e transferências internas; e 12. Resposta não punitiva ao erro ${ }^{(6-7)}$.

Os 42 itens do questionário que avaliam a CSP estão sob a forma de Escala de Likert, graduada em cinco pontos, que refletem o grau de concordância, de 1 (discordo totalmente ou nunca) a 5 (concordo totalmente e sempre). O grau de segurança do paciente foi medido pelo instrumento em uma escala diferente dos demais itens, sendo avaliado por uma escala de 5 pontos de 1 (muito ruim) a 5 (excelente), sendo o número de eventos de segurança notificados nos últimos 12 meses, medido por respostas de "nenhuma notificação" a "21 ou mais notificações"(6-7).

\section{AnÁlise E TRATAMENTO dOS DADOS}

Após a coleta dos dados, houve, de início, a realização de uma análise exploratória dos questionários por dois avaliadores para identificar e eliminar aqueles que apresentaram respostas altamente assimétricas ou elevado número de respostas ausentes $^{(8)}$. Os questionários foram ainda revisados quanto à presença de respostas duplas, ilegíveis ou rasuradas. Em caso de respostas duplas de significados convergentes, foi mantida, por consenso dos pesquisadores, a opção com maior escore. Quanto às respostas duplas de significado divergente, ilegíveis ou rasuradas, foram consideradas como informações ausentes na sentença.

A avaliação da CSP ocorreu por meio do percentual de respostas positivas obtidas em cada dimensão, conforme recomendações da AHRQ. Os resultados gerados permitiram identificar áreas frágeis, em potencial e fortes da segurança do paciente. São consideradas "áreas fortes da cultura de segurança do paciente" no hospital aquelas cujos itens escritos positivamente obtiveram $75 \%$ ou mais de respostas positivas ("concordo totalmente" ou "concordo"), ou aquelas cujos itens escritos negativamente obtiveram $75 \%$ ou mais das respostas negativas ("discordo totalmente" ou "discordo"). Da mesma forma, foram consideradas "áreas frágeis da cultura de segurança do paciente" e que necessitam de melhoria aquelas cujos itens obtiveram menos que $50 \%$ de respostas positivas. Os resultados entre $50 \%$ e menos de $75 \%$ foram considerados áreas em potencial para a segurança do paciente ${ }^{(8)}$.

Para prevenir erros de digitação e controlar a qualidade dos dados, foi realizada dupla digitação dos questionários, que foram inseridos em uma planilha em formato Microsoft ${ }^{\circledR}$ Excel ${ }^{\circledR}$, posteriormente transferidos para o software estatístico IBM Statistical Package for Social Sciences (SPSS) for Windows 20.0 ${ }^{\circledR}$. Para responder ao objetivo da pesquisa, utilizamos estatística descritiva e analítica, com os dados apresentados por meio de figuras e tabelas, contendo frequência absoluta (n) e relativa (\%), medidas de tendência central (mínimo e máximo) e medidas de dispersão (média e desvio padrão).

Para avaliar a confiabilidade e a consistência dos dados produzidos pelo instrumento, foi utilizado o teste Alpha de Cronbach ( $\alpha$ ), cujos valores acima de 0.70 são considerados aceitáveis ${ }^{(9)}$. Para determinar a associação estatística entre o número de EA e a nota geral da segurança do paciente entre as categorias profissionais de enfermagem e o local de trabalho, foi utilizado o teste do Qui-Quadrado de Pearson ou Exato de Fischer, sendo adotado o nível de significância de 5\%.

\section{Aspectos ÉTICOS}

As questões éticas seguiram as recomendações da Resolução no 466/2012 do Conselho Nacional de Saúde. Todos os participantes assinaram o termo de consentimento livre e esclarecido, sendo o projeto de pesquisa submetido e aprovado pelo Comitê de Ética em Pesquisa da Universidade Federal do Maranhão, sob parecer consubstanciado no 2.076.153 e CAEE: 66298017.0.0000.5087.

\section{RESULTADOS}

Participaram do estudo 163 profissionais de enfermagem, sendo a maioria do sexo feminino $(144=89,4 \%)$, com média de idade de 36,52 $( \pm 7,28)$ anos e no cargo de técnico de enfermagem $(121=74,2 \%)$. Em relação ao tempo de atuação profissional, houve predominância do período entre seis a dez anos $(69=47,6 \%)$ e carga horária de 20 a 39 horas semanais $(143=87,7 \%)$. A quase totalidade da amostra foi composta por profissionais que exerciam atividades em contato direto com o paciente $(160=99,3 \%)$.

O índice de Alpha de Cronbach ( $\alpha$ ) para as 12 dimensões avaliadas pelo instrumento HSOPSC obteve uma variação de 0.848 a 0.080 , indicando consistência por dimensões de altas a muito baixas. Observou-se que as dimensões "Retorno das informações e da comunicação sobre erros" e "Frequência de Eventos notificados" exibem valores acima de 0.7 , sendo, portanto, considerado bom. Já as dimensões "Passagem de plantão/turno e transferências internas" e "Abertura para comunicação” apresentaram os menores valores.

Tabela 1 - Distribuição do Alfa de Cronbach das dimensões do HSOPSC nas quatro Unidades de Terapia Intensiva de um hospital público - São Luís, MA, Brasil, 2017.

\begin{tabular}{lc}
\hline Dimensões & A \\
\hline 1- Trabalho em equipe dentro das unidades & 0,423 \\
$\begin{array}{l}\text { 2-Expectativas e ações de promoção de segurança do } \\
\text { supervisor/chefia }\end{array}$ & 0,165 \\
3- Aprendizado organizacional - melhoria contínua & 0,623 \\
4- Apoio da gestão hospitalar para segurança do paciente & 0,104 \\
5- Percepção geral da segurança do paciente & 0,152 \\
6- Retorno das informações e da comunicação sobre erros & 0,702 \\
7- Abertura para comunicação & 0,080 \\
8- Frequência de eventos notificados & 0,848 \\
9- Trabalho em equipe entre as unidades hospitalares & 0,294 \\
10- Adequação de profissionais & 0,402 \\
11- Passagem de plantão/turno e transferências internas & 0,261 \\
12- Resposta não punitiva ao erro & 0,479 \\
\hline
\end{tabular}

a: Alpha de Cronbach

A Figura 1 apresenta o percentual de respostas negativas, neutras e positivas das 12 dimensões da CSP, avaliadas de forma consolidada entre as quatro UTI pesquisadas. Essa figura representa as áreas fortes, as com potencial para a segurança e as áreas fracas. 


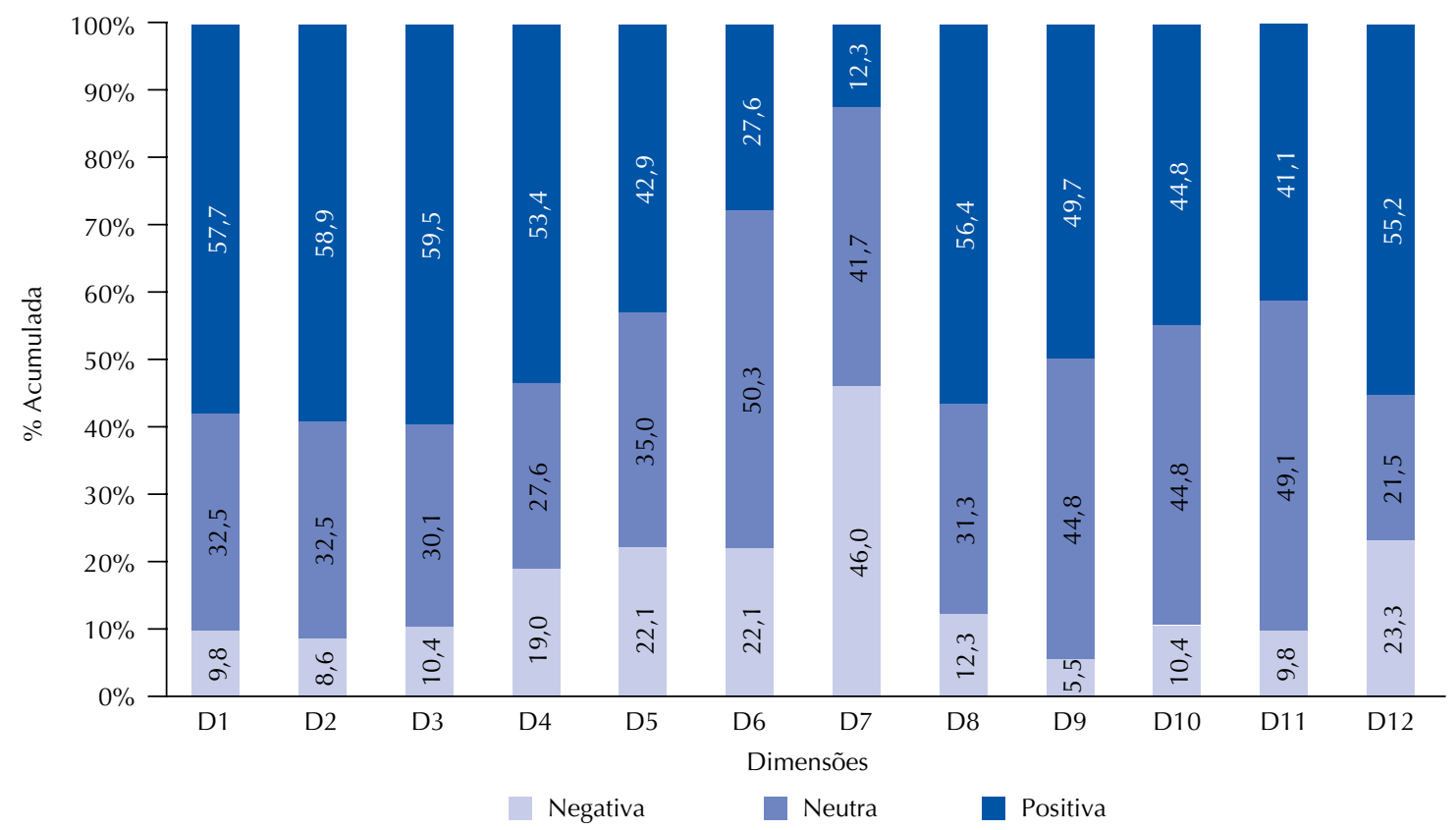

*D1: Trabalho em equipe na unidade; D2: Expectativas e ações do supervisor/chefia para a promoção da segurança do paciente; D3: Aprendizado organizacional - melhoria contínua; D4: Apoio da gestão hospitalar para segurança do paciente; D5: Percepção geral da segurança do paciente; D6: Feedback e comunicação sobre erros; D7: Abertura para comunicação; D8: Frequência de eventos comunicados; D9: Trabalho em equipe entre as unidades hospitalares; D10: Quadro de funcionários; D11: Transferências internas e passagem de plantão; D12: Resposta não punitiva ao erro.

Figura 1 - Percentual de respostas negativas, neutras e positivas das doze dimensões*, da versão traduzida, do Hospital Survey on Patient Safety Culture das quatro Unidades de Terapia Intensiva - São Luís, MA, Brasil, 2017.

Constatou-se na Figura 1 que nenhuma das 12 dimensões foi percebida pelas equipes de enfermagem das UTI como áreas fortes para a segurança do paciente. Ao considerar o percentual de respostas positivas, é possível identificar que as dimensões "aprendizado organizacional e melhoria contínua", "expectativas e ações de promoção de segurança dos supervisores/gerentes" e "trabalho em equipe dentro das unidades" apresentaram os maiores índices de respostas positivas, enquanto as dimensões "abertura para comunicação" e "retorno das informações e da comunicação sobre o erro" obtiveram os menores percentuais.
A Tabela 2 apresenta o grau de segurança do paciente e a sua distribuição entre categorias profissionais de enfermagem e local de trabalho. Observou-se que, quando solicitada a atribuir um grau geral de segurança do paciente, a maioria dos participantes $(72=47,0 \%)$ percebeu a segurança do paciente como muito boa e apenas $5(3,3 \%)$ como muito ruim. Nota-se que os resultados foram semelhantes nas quatro UTI. Entretanto, houve diferença estatística significativa $(\mathrm{p}<0,001)$ para o grau geral de segurança do paciente e a categoria da equipe de enfermagem, sendo a melhor avaliação do grau de segurança pelos técnicos de enfermagem comparado às notas dadas pelos enfermeiros.

Tabela 2 - Comparação do grau geral de segurança do paciente de acordo com as categorias da equipe de enfermagem e o local de trabalho em quatro Unidades de Terapia Intensiva de um hospital público - São Luís, MA, Brasil, 2017.

\begin{tabular}{|c|c|c|c|c|c|c|c|c|c|c|c|}
\hline & \multicolumn{2}{|c|}{ Excelente } & \multicolumn{2}{|c|}{ Muito boa } & \multicolumn{2}{|c|}{ Regular } & \multicolumn{2}{|c|}{ Ruim } & \multicolumn{2}{|c|}{ Muito ruim } & \multirow{2}{*}{ p-valor** } \\
\hline & $n$ & $\%$ & $\mathbf{N}$ & $\%$ & $\mathbf{n}$ & $\%$ & $\mathbf{n}$ & $\%$ & $\mathbf{n}$ & $\%$ & \\
\hline \multicolumn{12}{|l|}{ Profissionais* } \\
\hline Enfermeiro & 0 & 0,0 & 17 & 11,1 & 17 & 11,1 & 2 & 1,3 & 2 & 1,3 & \multirow[t]{3}{*}{$<0,001$} \\
\hline Técnico de enfermagem & 29 & 19,0 & 55 & 35,9 & 26 & 17,0 & 2 & 1,3 & 3 & 2,0 & \\
\hline Total & 29 & 19,0 & 72 & 47 & 43 & 28,1 & 4 & 2,6 & 5 & 3,3 & \\
\hline \multicolumn{12}{|l|}{ Local* } \\
\hline UTI Cardiológica & 9 & 5,9 & 14 & 9,0 & 9 & 5,9 & 2 & 1,3 & 1 & 0,6 & \multirow{4}{*}{0,83} \\
\hline UTI Cirúrgica & 9 & 5,9 & 16 & 10,4 & 9 & 5,9 & 0 & 0,0 & 2 & 1,3 & \\
\hline UTI Geral I & 6 & 3,9 & 20 & 13,0 & 13 & 8,5 & 1 & 0,6 & 1 & 0,6 & \\
\hline UTI Geral II & 5 & 3,2 & 22 & 14,2 & 12 & 7,8 & 2 & 1,3 & 1 & 0,6 & \\
\hline Total & 29 & 18,9 & 72 & 46,6 & 42 & 28,1 & 5 & 3,2 & 5 & 3,1 & \\
\hline
\end{tabular}

*Foram excluídos os itens ausentes

**Teste do Qui-Quadrado de Pearson 
Quando questionados sobre o número de notificações de eventos nos últimos 12 meses, observa-se na Tabela 3 que a maioria $(112=68,7 \%)$ não notificou qualquer evento. Segundo os resultados apresentados, houve diferença estatística $(p<0,001)$ entre número de notificação de eventos e categoria profissional de enfermagem, sendo mencionado um número maior de notificações pelos enfermeiros, comparados aos técnicos de enfermagem.

Tabela 3 - Comparação do número de eventos adversos notificados de acordo com as categorias da equipe de enfermagem e o local de trabalho em quatro Unidades de Terapia Intensiva de um hospital público - São Luís, MA, Brasil, 2017.

\begin{tabular}{|c|c|c|c|c|c|c|c|c|c|c|c|c|c|}
\hline & \multicolumn{2}{|c|}{ Nenhum } & \multicolumn{2}{|c|}{1 a 2} & \multicolumn{2}{|c|}{3 a 5} & \multicolumn{2}{|c|}{6 a 10} & \multicolumn{2}{|c|}{11 a 20} & \multicolumn{2}{|c|}{21 ou mais } & \multirow{2}{*}{ p-valor** } \\
\hline & $\mathbf{n}$ & $\%$ & $\mathbf{n}$ & $\%$ & $\mathbf{n}$ & $\%$ & $\mathbf{n}$ & $\%$ & $\mathbf{n}$ & $\%$ & $\mathbf{n}$ & $\%$ & \\
\hline \multicolumn{14}{|l|}{ Profissionais* } \\
\hline Enfermeiro & 16 & 9,9 & 10 & 6.2 & 5 & 3,0 & 5 & 3,0 & 2 & 1,2 & 3 & 1,9 & \multirow[t]{2}{*}{$<0,001$} \\
\hline Técnico de enfermagem & 96 & 59,2 & 17 & 10,5 & 4 & 2,5 & 3 & 2,0 & 0 & 0,0 & 1 & 0,6 & \\
\hline Total & 112 & 69,1 & 27 & 16,7 & 9 & 5,5 & 8 & 5,0 & 2 & 1,2 & 4 & 2,5 & \\
\hline \multicolumn{14}{|l|}{ Local* } \\
\hline UTI Cardiológica & 26 & 16,0 & 7 & 4,3 & 1 & 0,6 & 1 & 0,6 & 0 & 0,0 & 1 & 0,6 & \multirow{4}{*}{0,62} \\
\hline UTI Cirúrgica & 24 & 14,7 & 9 & 5,5 & 2 & 1,2 & 2 & 1,2 & 0 & 0,0 & 2 & 1,2 & \\
\hline UTI Geral I & 31 & 19,0 & 4 & 2,4 & 4 & 2,5 & 4 & 2,5 & 0 & 0,0 & 1 & 0,6 & \\
\hline UTI Geral II & 31 & 19,0 & 7 & 4,3 & 3 & 1,9 & 1 & 0,6 & 2 & 1,2 & 0 & 0,0 & \\
\hline Total & 112 & 68,7 & 27 & 16,5 & 10 & 6,2 & 8 & 4,9 & 2 & 1,2 & 4 & 2,4 & \\
\hline
\end{tabular}

*Foram excluídos os itens ausentes

**Teste Exato de Fischer

\section{DISCUSSÃO}

O estudo revelou que nenhuma dimensão avaliada pelo instrumento HSOPSC foi considerada uma área forte. Porém, a maioria se mostrou como áreas em potenciais no contexto da CSP.

Em relação à confiabilidade, outros estudiosos também identificaram baixos valores para o Alpha de Cronbach em algumas dimensões da CSP. Esses valores variaram de 0,52 a 0,91 no estudo de validação do instrumento para a versão brasileira ${ }^{(9)}$, e entre 0,20 a 0,8 em pesquisa realizada em um hospital universitário no Nordeste ${ }^{(10)}$. A AHRQ ao realizar estudos de validação do instrumento nos Estados Unidos, obteve valores de 0,62 a 0,85, demonstrando uma variação entre as dimensões que pode estar relacionada às características da população e à variabilidade de respostas dos participantes ${ }^{(8)}$.

As repostas positivas para as dimensões da CSP mostram que os profissionais de enfermagem percebem o erro como uma oportunidade de aprendizado, visto que a dimensão "Aprendizado organizacional e melhoria contínua" obteve o maior percentual de respostas positivas. Esse achado está em consonância com a literatura internacional ${ }^{(11-13)}$, tendo essa dimensão apresentado valores ainda superiores aos encontrados na pesquisa. Sabe-se que há necessidade de capacitações em serviço que promovam o conhecimento em segurança do paciente e estimulem os profissionais na adesão a estratégias de identificação de riscos e adoção de medidas capazes de prevenir ou reduzir a ocorrência de $\mathrm{EA}^{(14)}$. Esse aprendizado deve ser gerenciado a partir de ações voltadas à construção de uma CSP positiva, retirando o foco da culpabilização para o aprendizado a partir do erro, de modo a fornecer meios para que os profissionais reconheçam e possam evitar novos eventos ${ }^{(10)}$.

Outra dimensão com grande percentual de respostas positivas foi "Expectativas e ações do supervisor/chefia para a promoção da segurança do paciente". Esse resultado demonstra que o empenho da instituição em promover ações relacionadas à segurança do paciente é reconhecido pelos funcionários, já que suas sugestões para a melhoria da qualidade da assistência são levadas em consideração. Em outras instituições no Brasil ${ }^{(10,15)}$, o papel da gestão na melhoria da CSP não foi percebido pela equipe de saúde, demonstrando que o PNSP tem demandado esforços no sentido de fortalecer o cuidado seguro.

Desse modo, para construir uma cultura de segurança positiva, os gestores precisam se comprometer com a segurança do paciente e ser um modelo a seguir, pois, embora a CSP esteja pautada em valores e atitudes individuais e coletivas, as instituições de saúde devem prover um ambiente que garanta os meios necessários para a efetiva segurança do cuidado, abrangendo desde a infraestrutura aos recursos materiais, tecnológicos, financeiros e humanos ${ }^{(14,16)}$. Além disso, a promoção de debates entre gerentes e equipes se faz necessária, posto que os líderes influenciam diretamente nessas questões ao estabelecerem metas e estratégias para $o$ atendimento, com apoio e promoção de uma cultura de desenvolvimento, além de gerenciamento de problemas e planejamento de recursos voltados para a qualidade e segurança do paciente a partir da percepção dos profissionais que estão na linha de frente do cuidado ${ }^{(17)}$. O trabalho em equipe, percebido como uma área em potencial, e o respeito mútuo são características essenciais ao cuidado seguro, pois 
contribuem para o desenvolvimento de uma assistência qualificada que reflete positivamente no cotidiano de trabalho, influenciando a promoção da CSP, visto que o aprimoramento dos profissionais está atrelado à boa cooperação entre as equipes ${ }^{(18)}$.

As dimensões identificadas como frágeis estão relacionadas à comunicação, seja dentro ou entre equipes. Sabe-se que a comunicação efetiva, baseada no compartilhamento e na boa interação entre as equipes, gera um impacto positivo nos cuidados de enfermagem. Assim, percebe-se que para avançar na promoção de uma CSP forte é necessário trabalhar as dimensões frágeis, aperfeiçoando o retorno das informações e incentivando a notificação de eventos.

Estratégias multidisciplinares como protocolos de transferências, formulários de admissões, com informações claras, objetivas e de forma destacada em prontuários têm melhorado o processo de comunicação entre as equipes ${ }^{(19)}$. Sendo assim, aprimorar os processos de trabalho por meio da comunicação efetiva é ferramenta importante no combate a falhas e deve ser incentivada para o alcance da qualidade da assistência e segurança do paciente.

Percebe-se que os profissionais pouco notificam os incidentes de saúde, existindo ainda uma diferença significativa em relação à categoria que os identifica. Pesquisa realizada no leste de Gana mostrou que mais de 70\% dos profissionais entrevistados não notificaram qualquer evento adverso nos últimos doze meses, cenário semelhante ao brasileiro com estudo apontando para a subnotificação desses eventos $^{(20-21)}$. Dentre os principais motivos relatados pelos profissionais de saúde para não realizarem as notificações, encontram-se o medo da pressão por parte dos gestores, a sobrecarga de trabalho, o esquecimento, a desvalorização dos EA, a falta de conhecimento sobre como realizar a notificação e a falta de feedback quando essas notificações são realizadas ${ }^{(22)}$.

A centralização do processo de notificação também foi relatada pelos profissionais, sendo os enfermeiros mencionados como principais atores desse processo $^{(22)}$, razão pela qual se tem maior número de notificações por essa categoria. Esse achado foi identificado em outros estudos sobre CSP em ambientes de terapia intensiva ${ }^{(21,23)}$, em que os técnicos de enfermagem foram os profissionais que mais selecionaram a opção "nenhum evento" notificado nos últimos 12 meses, indicando que a prática de notificações ainda não foi enraizada pela equipe, cuja cultura vigente, bem como o sentimento de medo/culpa, influencia na comunicação dos eventos.

O processo de notificação necessita de atenção e investimento dos gestores, podendo ser melhor estruturado nos serviços de terapia intensiva, pois deve ser visto como medida de identificação e prevenção de incidentes ${ }^{(24)}$. A constatação do erro e a sua notificação são fundamentais para o desenvolvimento e a implementação de ações e medidas preventivas para o estabelecimento da saúde do paciente, além de servirem como fonte de dados para a análise da ocorrência do evento ${ }^{(25)}$. Esse comprometimento é muito importante, pois os incidentes relacionados à assistência estão presentes, porém, são pouco visualizados. Os erros são difíceis de discutir, uma vez que ainda é prevalente a cultura da culpabilização e da punição.

De modo geral, os profissionais de enfermagem avaliaram a segurança do paciente como muito boa, sendo que os técnicos de enfermagem tiveram melhor percepção do que os enfermeiros, o que mostra uma diferença significativa entre as categorias. Pesquisas revelam que enfermeiros com cargo de gerência tendem a associar um maior grau de segurança do paciente quando comparados a enfermeiros assistenciais $^{(17,21)}$. Entretanto, o que se observou vai em direção contrária, visto que os técnicos de enfermagem que estão diretamente ligados à assistência aos pacientes avaliaram melhor a CSP.

Observa-se que, nos locais "onde a cultura de segurança é desigual entre os trabalhadores, há necessidade de valorização e motivação profissional, discussões periódicas sobre o processo de trabalho e práticas incentivadoras do cuidado seguro"(14). É possível que os técnicos de enfermagem das UTI analisadas se sintam mais valorizados, impactando na avaliação da segurança do paciente.

Os resultados identificados assemelham-se aos de outros estudos realizados em UTI pelo país ${ }^{(17,21)}$, nos quais as opções "excelente" e "muito boa" foram assinaladas em sua maioria por técnicos de enfermagem. Além disso, quando comparados com dados internacionais, observamos também uma variação da nota de acordo com o cargo, em que gestores pontuam de forma mais alta que profissionais da assistência ${ }^{(26)}$. Denota-se a importância da disponibilidade de infraestrutura, de recursos materiais e humanos capacitados e em quantidade suficiente para a realização da assistência de enfermagem, principalmente nos serviços de terapia intensiva em que há necessidade de rapidez e efetividade no atendimento.

Como mencionado anteriormente, a CSP foi avaliada nas UTI como muito boa e a análise das dimensões do HSOPSC aponta a sua maioria como áreas potenciais para uma cultura justa. Reconhecer que os serviços de saúde são diretamente influenciados pela CSP e que esta deve fazer parte dos ambientes de cuidado, com o planejamento de ações para a prevenção dos erros, é um importante passo para a melhoria da qualidade da assistência ${ }^{(1)}$.

As diferenças sociais, políticas e econômicas influenciam diretamente na avaliação da CSP. Em países desenvolvidos como a China e os Estados Unidos, essa cultura é considerada mais positiva. Estudo com países IberoAmericanos, incluindo o Brasil, demonstrou os esforços dessas nações diante da ocorrência de EA, embora relate que países europeus estão mais preparados para análise e intervenção frente a esses eventos ${ }^{(27)}$. O Brasil ainda apresenta um contraste de gestão em seu sistema de saúde: quando comparando a gestão pública com a gestão privada, a administração privada apresenta melhor média de segurança, embora nenhuma tenha atingido a fortaleza, quando analisadas por dimensões.

Assim, para alcançar os resultados almejados no cuidado livre ou com o mínimo de danos possível, é "fundamental que a assistência seja prestada em observância à singularidade e à realidade multifacetada de cada paciente, além do apoio 
da gestão a qual deve ser operante e efetiva nos serviços de saúde" (28). Os investimentos em infraestrutura e em educação, base para os processos de trabalho, são indispensáveis para se atingir e manter as condições mínimas de segurança em organizações de alto risco, como as instituições de saúde.

Os resultados apresentados trazem contribuições importantes ao conhecimento sobre segurança do paciente, entendido como necessário para o desenvolvimento de ações nas instituições de saúde, quando associada à visão dos profissionais com dados objetivos, como descritos neste estudo. Entretanto, considera-se como limitações desta pesquisa o fato de a CSP ter sido avaliada apenas com a equipe de enfermagem, bem como o tempo disponível para a resposta dos questionários, devido à rotina de trabalho e à extensão do instrumento.

\section{CONCLUSÃO}

$\mathrm{Na}$ percepção dos profissionais de enfermagem, não foi possível identificar nenhuma área forte nas dimensões que constituem a CSP, indicando que tal cultura precisa ser desenvolvida. Quanto ao grau geral de segurança do paciente, a maioria dos participantes a considerou como muito boa, sendo observadas diferenças de percepções entre enfermeiros e técnicos de enfermagem. Tal diferença também foi identificada no processo de notificação de incidentes em saúde, havendo de modo geral subnotificação dos EA. Os resultados apontam a necessidade da participação ativa de gestores e profissionais no desenvolvimento de uma cultura justa, bem como constituem um diagnóstico para a implementação de ações eficazes para a melhoria da segurança do paciente.

\section{RESUMO}

Objetivo: Analisar a cultura de segurança do paciente entre profissionais de enfermagem da terapia intensiva. Método: Estudo transversal realizado em Unidades de Terapia Intensiva de hospital público. A coleta de dados foi realizada de setembro a outubro de 2017 com profissionais de enfermagem, aplicando o questionário Hospital Survey on Patient Safety Culture. Foram realizados os testes Alpha de Cronbach, Qui-Quadrado de Pearson ou Exato de Fischer (nível de significância de 5\%). Resultados: A amostra final foi composta por 163 profissionais de enfermagem. Não foram observadas áreas fortes para a segurança do paciente. As dimensões "trabalho em equipe na unidade", "expectativas e ações do supervisor/chefia para a promoção da segurança do paciente" e "aprendizado organizacional e melhoria contínua" apresentaram os maiores índices de respostas positivas, enquanto as dimensões "abertura para comunicação" e "retorno das informações e da comunicação sobre o erro" obtiveram os menores percentuais. O grau geral de segurança do paciente foi considerado muito bom $(72=47 \%)$ e observou-se subnotificação dos eventos, sendo a maioria realizada pelos enfermeiros. Conclusão: Nenhuma dimensão avaliada foi considerada área forte, porém, a maioria mostrou-se como áreas em potenciais para a cultura de segurança do paciente.

\section{DESCRITORES}

Segurança do Paciente; Cultura Organizacional; Unidades de Terapia Intensiva; Enfermagem.

\section{RESUMEN}

Objetivo: Analizar la cultura de seguridad del paciente entre los profesionales de enfermería de cuidados intensivos. Método: Se trata de un estudio transversal realizado en Unidades de Cuidados Intensivos de un hospital público. La recolección de datos se llevó a cabo con el Cuestionario Hospitalario sobre la Cultura de Seguridad del Paciente entre septiembre y octubre de 2017, con profesionales de enfermería. Se aplicaron las pruebas Alfa de Cronbach, Chi-cuadrado de Pearson o Exacta de Fischer (nivel de significación del 5\%). Resultados: La muestra final estaba compuesta por 163 profesionales de enfermería. No se observaron áreas fuertes en la seguridad del paciente. Las dimensiones "trabajo en equipo de la unidad", "expectativas y acciones del supervisor/ liderazgo para promover la seguridad del paciente" y "aprendizaje organizativo y mejora continua” mostraron los índices más altos de respuestas positivas, mientras que las dimensiones "apertura a la comunicación" y "respuestas a la información (feedback) y comunicación sobre el error” obtuvieron los porcentajes más bajos. El nivel de seguridad general del paciente se consideró como muy bueno, 72 (47\%), y se observó una infradeclaración de sucesos, la mayoría de los cuales realizados por los enfermeros. Conclusión: Ninguna dimensión evaluada ha sido considerada un área fuerte; sin embargo, la mayoría se mostró como un área potencial para la cultura de seguridad del paciente.

\section{DESCRIPTORES}

Seguridad del Paciente; Cultura Organizacional; Unidades de Cuidados Intensivos; Enfermería.

\section{REFERÊNCIAS}

1. Campelo CL, Sousa SMA, Silva LDC, Dias RS, Azevedo PR, Nunes FDO, et al. Patient safety culture and the cultural nursing care. Rev Enferm UFPE On Line. 2018;12(9):2500. https://doi.org/10.5205/1981-8963-v12i9a235048p2500-2506-2018.

2. Brasil. Ministério da Saúde. Agência Nacional de Vigilância Sanitária. Documento de referência para o Programa Nacional de Segurança do Paciente. Brasília, DF: Agência Nacional de Vigilância Sanitária; 2014.

3. Gama ZA, Batista AM, Silva IG, Souza RM, Freitas MR. [Cross-cultual adaptation of the Brazilian version of the Hospital Survey on Patient Safety Culture: opportunities for improvement]. Cad Saúde Pública. 2013;29(7):1473-5. Portuguese. https://doi.org/10.1590/S0102311 X2013001100021

4. Maia CS, Freitas DR, Gallo LG, Araújo WN. Registry of adverse events related to health care that results in deaths in Brazil, $2014-2016$. Epidemiol Serv Saude. 2018;27(2):e2017320. https://doi.org/10.5123/S1679-49742018000200004

5. Duarte SC, Stipp MA, Silva MM, Oliveira FT. Adverse events and safety in nursing care. Rev Bras Enferm. 2015;68(1):144-54. https://doi.org/10.1590/0034-7167.2015680120p

6. Oliveira AC, Garcia PC, Nogueira LS. Nursing workload and occurrence of adverse events in intensive care: a systematic review. Rev Esc Enferm USP. 2016;50(4):683-94. https://doi.org/10.1590/S0080-623420160000500020 
7. Andrade LE, Lopes JM, Souza Filho MC, Vieira Júnior RF, Farias LP, Santos CC, et al. [Patient safety culture in three Brazilian hospitals with different types of management]. Cienc Saúde Colet. 2018;23(1):161-72. Portuguese. https://doi.org/10.1590/1413-81232018231.24392015

8. Agency for Healthcare Research and Quality. Sorra J, Famolaro T, Dyer N, Nelson D, Khanna K. Hospital survey on patient safety culture: 2010 user comparative database report [Internet]. Rockville: PSNet; 2010 [cited 2020 Aug 24]. Available from: https://psnet.ahrq.gov/issue/ hospital-survey-patient-safety-culture-2010-user-comparative-database-report

9. Reis CT, Laguardia J, Vasconcelos AG, Martins M. Reliability and validity of the Brazilian version of the Hospital Survey on Patient Safety Culture (HSOPSC): a pilot study. Cad Saúde Pública. 2016;32(11):e00115614. https://doi.org/10.1590/0102-311x00115614

10. Tavares AP, Moura EC, Avelino FV, Lopes VC, Nogueira LT. Patient safety culture from the perspective of the nursing team. Rev Rene. 2018;19:e3152. https://doi.org/10.15253/2175-6783.2018193152

11. Khoshakhlagh AH, Khatooni E, Akbarzadeh I, Yazdanirad S, Sheidaei A. Analysis of affecting factors on patient safety culture in public and private hospitals in Iran. BMC Health Serv Res. 2019;19(1):1009. https://doi.org/10.1186/s12913-019-4863-x

12. Ammouri AA, Tailakh AK, Muliira JK, Geethakrishnan R, Al Kindi SN. Patient safety culture among nurses. Int Nurs Rev. 2015;62(1):102-10. https://doi.org/10.1111/inr.12159

13. Alquwez N, Cruz JP, Almoghairi AM, Al-Otaibi RS, Almutairi KO, Alicante JG, et al. Nurses' perceptions of patient safety culture in three hospitals in Saudi Arabia. J Nurs Scholarsh. 2018;50(4):422-31. https://doi.org/10.1111/jnu.12394

14. Raimondi DC, Bernal SC, Oliveira JL, Matsuda LM, Raimondi DC, Bernal SC, et al. Patient safety culture in primary health care: analysis by professional categories. Rev Gaúch Enferm. 2019;40(spe):e20180133. https://doi.org/10.1590/1983-1447.2019.20180133

15. Ribeiro AC, Nogueira PC, Tronchin DM, Rossato V, Serpa LF. Patient safety culture: perception of nurses in a cardiopneumology reference center. Texto Contexto Enferm. 2019;28:e20180118. https://doi.org/10.1590/1980-265x-tce-2018-0118

16. Silva ND, Barbosa AP, Padilha KG, Malik AM. Patient safety in organizational culture as perceived by leaderships of hospital institutions with different types of administration. Rev Esc Enferm USP. 2016;50(3):490-7. https://doi.org/10.1590/S0080-623420160000400016

17. Mello JF, Barbosa, Faria SF. Patient safety culture in an intensive care unit: the perspective of the nursing team. Rev Eletr Enferm. 2017;19(1):19.a07. https://doi.org/10.5216/ree.v19.38760

18. Martins CC, Santos VE, Pereira MS, Santos NP. The nursing team's interpersonal relationships V. stress: limitations for practice. Cogitare Enferm [Internet]. 2014 [cited 2020 Aug 24];19(2):287-93. Available from: https://revistas.ufpr.br/cogitare/article/viewFile/36985/22757

19. Olino L, Gonçalves AC, Strada JK, Vieira LB, Machado ML, Molina KL, et al. Effective communication for patient safety: transfer note and Modified Early Warning Score. Rev Gaúcha Enferm. 2019;40(spe):e20180341. https://doi.org/10.1590/1983-1447.2019.20180341

20. Akologo A, Abuosi AA, Anaba EA. A cross-sectional survey on patient safety culture among healthcare providers in the Upper East region of Ghana. PLoS One. 2019;14(8):e0221208. https://doi.org/10.1371/journal.pone.0221208

21. Minuzzi AP, Salum NC, Locks MO. Assessment of patient safety culture in intensive care from the health team's perspective. Texto Contexto Enferm. 2016;25(2):e1610015. https://doi.org/10.1590/0104-07072016001610015

22. Alves MF, Carvalho DS, Albuquerque GS. Barriers to patient safety incident reporting by Brazilian health professionals: an integrative review. Cienc Saúde Coletiva. 2019;24(8):2895-908. https://doi.org/10.1590/1413-81232018248.23912017

23. Tomazoni A, Rocha PK, Kusahara DM, Souza AI, Macedo TR. Evaluation of the patient safety culture in neonatal intensive care. Texto Contextot Enferm. 2015;24(1):161-9. https://doi.org/10.1590/0104-07072016001610015

24. Fassarella CS, Silva LD, Camerini FG, Figueiredo MD. Nurse safety culture in the services of a university hospital. Rev Bras Enferm. 2019;72(3):767-73. https://doi.org/10.1590/0034-7167-2018-0376

25. Abreu IM, Rocha RC, Avelino FV, Guimarães DB, Nogueira LT, Madeira MZ, et al. Patient safety culture at a surgical center: the nursing perception. Rev Gaúcha Enferm. 2019;40(spe):e20180198. https://doi.org/10.1590/1983-1447.2019.20180198

26. Danielsson M, Nilsen P, Rutberg H, Arestedt K. A national study of patient safety culture in hospitals in Sweden. J Patient Saf. 2019;15(4):328-33. https://doi.org/10.1097/PTS.0000000000000369

27. Mira JJ, Carrillo I, García-Elorrio E, Andrade-Lourenção DC, Pavan-Baptista PC, Franco-Herrera AL, et al. What Ibero-American hospitals do when things go wrong? A cross-sectional international study. Int J Qual Health Care. 2020;32(5):313-8. https://doi.org/10.1093/ intqhe/mzaa031

28. Gomes AT, Ferreira MA Jr, Salvador PT, Bezerril MD, Chiavone FB, Santos VE. Safety of the patient in an emergency situation: perceptions of the nursing team. Rev Bras Enferm. 2019;72(3):753-9. https://doi.org/10.1590/0034-7167-2018-0544

Fundação de Amparo à Pesquisa e ao Desenvolvimento Científico e Tecnológico do Maranhão (Fapema). Process no Universal - 01624/16. 